\title{
Synaptic Integration of Olfactory Information in Mouse Anterior Olfactory Nucleus
}

\author{
Huimeng Lei, ${ }^{1,2}$ Richard Mooney, ${ }^{2}$ and Lawrence C. Katz ${ }^{1,2 \dagger}$ \\ ${ }^{1}$ Howard Hughes Medical Institute and ${ }^{2}$ Department of Neurobiology, Duke University Medical Center, Durham, North Carolina 27710
}

\begin{abstract}
Individual odorants activate only a small fraction of mitral cells in the mouse main olfactory bulb (MOB). Odor mixtures are represented by a combination of activated mitral cells, forming reproducible activation maps in the olfactory bulb. However, how the activation of a cohort of narrowly tuned mitral cells by odor mixtures is read out synaptically by neurons in higher-level olfactory structures, such as the anterior olfactory nucleus (AON), is mostly unknown. In the current study, we used intracellular and extracellular recordings to examine and compare responses of $\mathrm{AON}$ neurons and $\mathrm{MOB}$ mitral cells to a panel of structurally diverse odorants presented either as mixtures or as individual components. We found that a majority of individual AON neurons could be synaptically activated by several mixtures of structurally dissimilar components and by several dissimilar components in an effective mixture. The suprathreshold response of an AON neuron to an effective mixture often exceeded the sum of its suprathreshold responses to all of the components in that mixture, indicating a nonlinear combinatorial interaction. In contrast to the broad responsiveness of AON neurons, the majority of mitral cells were activated by only one or two components in a single mixture. The broader responsiveness of AON neurons relative to mitral cells suggests that individual AON neurons synaptically integrate several functionally distinct mitral cell inputs.
\end{abstract}

Key words: olfactory; mouse; synaptic integration; tuning; anterior olfactory nucleus (AON); main olfactory bulb (MOB); in vivo intracellular

\section{Introduction}

Natural odorants important to intraspecies communication, food source localization, and predator detection are complex mixtures comprising hundreds of components. Therefore, the olfactory system must solve the competing challenges of detecting individual components and forming a coherent representation of the olfactory object. In the rodent main olfactory bulb (MOB), individual mitral cells respond to one or, at most, a few structurally similar components of complex natural or artificial odorant mixtures (Lin da et al., 2005, 2006). This finding suggests that initial stages of olfactory processing involve decomposition of a complex mixture into a combination of individual odor features (Wilson, 2000b; Haberly, 2001). However, humans have limited ability to discriminate individual components in odor mixtures (Livermore and Laing, 1996) and instead perceive complex mixtures as unitary olfactory objects. This quality of olfactory perception suggests that individual odorant features are integrated at higher levels of the olfactory system (Perez-Orive et al., 2002; Zou and Buck, 2006) (for review, see Wilson and Stevenson, 2003; Brunjes et al., 2005), although the nature of such integration remains enigmatic.

Received June 20, 2006; revised Sept. 7, 2006; accepted 0ct. 13, 2006.

This work was supported by National Institutes of Health Grant DC005671 (R.D.M.). We dedicate this paper to the memory of Dr. Lawrence C. Katz. We thank David Fitzpatrick, Liqun Luo, Ian Davison, and Stephen Shea for helpful discussion and constructive comments on previous versions of this manuscript.

${ }^{\dagger}$ Deceased, Nov. 25, 2005.

Correspondence should be addressed to Dr. Richard Mooney, Department of Neurobiology, Box 3209, Duke University Medical Center, Durham, NC 27710. E-mail: Mooney@neuro.duke.edu.

D01:10.1523/JNEUROSCI.2598-06.2006

Copyright $\odot 2006$ Society for Neuroscience $\quad$ 0270-6474/06/2612023-10\$15.00/0
One idea is that this integration is achieved in the olfactory cortex by merging information from distinct populations of mitral cells, a view supported by several lines of evidence. Axon terminal fields arising from mitral cells in different glomeruli partially overlap in their central targets (Zou et al., 2001). Immediate-early gene (IEG) studies show that odorants likely to activate separate populations of mitral cells activate distinct but partially overlapping regions of the olfactory cortex (Illig and Haberly, 2003; Zou et al., 2005). Moreover, IEG activation in some olfactory cortical neurons depends on odor combinations, suggesting a requirement for simultaneous input from separate mitral cell populations (Zou and Buck, 2006). These results suggest that individual neurons above the level of the MOB are likely to respond to a broader range of individual odorants, reflecting convergent input from functionally different classes of mitral cells. There is, however, surprisingly little evidence regarding odorant selectivity of individual olfactory cortical neurons and how this compares with the selectivity of individual mitral cells. Given the large size of odor space, attempting to define the response properties of single neurons in the olfactory cortex or MOB is a daunting task. However, if there are significant differences in the breadth of tuning of cortical and mitral cells, this should be evident in comparing their responses to a single set of odorants or mixtures representing diverse structural and perceptual categories.

To address this issue, we measured odor-evoked responses of individual neurons in the anterior olfactory nucleus (AON), the lowest level within the olfactory cortical hierarchy and a recipient of direct inputs from mitral cells in the MOB (Neville and Haberly, 2004). Using in vivo intracellular recordings in anesthe- 
tized mice, we found that most AON neurons were synaptically activated by several structurally dissimilar components of multiple diverse odor mixtures. The suprathreshold response of an AON neuron to an effective mixture often exceeded the sum of its responses to all of the components in that mixture, indicative of a nonlinear combinatorial interaction. In contrast to the broad response profiles of $\mathrm{AON}$ neurons, in vivo extracellular and intracellular recordings revealed that most mitral cells were activated by only one or two components in a single mixture. The broader responsiveness of $\mathrm{AON}$ neurons relative to mitral cells supports the idea that individual AON neurons combine multiple odor features by integrating input from functionally different classes of mitral cells.

\section{Materials and Methods}

All animal experiments were performed according to a protocol approved by the Duke University Institutional Animal Care and Usage Committee.

\section{Animals and anesthesia}

Adult (10-20 weeks) C57BL/6 female mice were used in all experiments. To reduce respiratory secretion and block bradycardia associated with anesthesia, atropine $(0.4 \mathrm{mg} / \mathrm{ml}, 0.05 \mathrm{mg} / \mathrm{kg})$ was injected intraperitoneally before anesthesia. Animals were initially anesthetized with ketamine $(200 \mathrm{mg} / \mathrm{kg})$ and xylazine $(50 \mathrm{mg} / \mathrm{kg})$ by intraperitoneal injection and maintained on sevofluorane $\left(1-2 \%\right.$ in $\left.100 \% \mathrm{O}_{2}\right)$. The depth of anesthesia was monitored by heart and respiration rate. Anesthetized freely breathing mice were fixed in an adjustable stereotaxic apparatus and kept warm $\left(37^{\circ} \mathrm{C}\right)$ with an electric heating pad. Breathing was monitored by measuring the movement of chest with a strain gauge (KFG-3-120; Omega, Stamford, CT) connected to a bridge module (BCM-1; Omega) and an amplifier (DMD-465; Omega).

\section{Odor stimulation}

Seven artificial mixtures each with six monomolecular components (except mixture 6, which contained four components) (Table 1) were used as odor stimuli for both intracellular and extracellular recording experiments. All mixtures and their components were diluted in mineral oil to achieve a headspace concentration of $10 \mathrm{ppm}$ (parts per million of vapor pressure) in the vials and were further diluted to $1 \mathrm{ppm}$ in the airflow. Odorants were delivered in random order by a robotic 49-channel olfactometer (model 7200; I \& J Fisnar, Fair Lawn, NJ) at a $300 \mathrm{ml} / \mathrm{min}$ flow rate. The duration for each trial of odorant application was $2 \mathrm{~s}$ with at least $60 \mathrm{~s}$ intervals controlled by solenoid valves to avoid habituation (Wilson, 2000a). To keep a constant flow rate, another stream of pure oxygen with the same flow rate as that used for odor delivery was applied between odor applications to compensate for the flow rate change.

\section{Electrophysiology}

Intracellular recording. The AON is a spherical structure $2.5-3.8 \mathrm{~mm}$ anterior to bregma, $0.6-1.6 \mathrm{~mm}$ lateral to the sagittal suture, $2-4 \mathrm{~mm}$ below the cranial surface, ventrally located posterior to the MOB. A small hole with a diameter of $0.3-0.5 \mathrm{~mm}$ was opened on the skull above the dorsal surface of the AON. In some experiments, electrodes were inserted into the AON with an angle of $52-55^{\circ}$ to the dorsal surface through an aperture over the MOB. Sharp intracellular recording electrodes (100$150 \mathrm{M} \Omega$ ) filled with $2 \mathrm{M}$ potassium acetate and $4 \%$ neurobiotin (Vector Laboratories, Burlingame, CA) were directed to the AON to search for cells. Odorants were only tested for cells with a stable resting membrane potential less than $-60 \mathrm{mV}$ and action potentials larger than $60 \mathrm{mV}$. The resting membrane potential of some cells was maintained at a stable value by tonic current injection. Signals were low-pass filtered at $3 \mathrm{kHz}$, amplified $10 \times$ by the AxoClamp 2B intracellular amplifier (Molecular Devices, Union City, CA), and digitized at $10 \mathrm{kHz}$ (Spike2 software; Cam- bridge Electronic Design, Cambridge, UK). The same procedure was used for intracellular recordings of mitral cells, but electrode access was achieved through a small hole on the skull above the dorsal surface of the MOB.

Extracellular recording. Quartz-platinum/tungsten microelectrodes (1.5-3 M $\Omega$; Thomas Recording, Giessen, Germany) were used for extracellular recording in the MOB. Isolated single units were filtered between $500 \mathrm{~Hz}$ and $5 \mathrm{kHz}$ and amplified $500 \times$ using a Thomas Recording system (MiniMatrix). Spike2 software was used for data acquisition and analysis.

\section{Histology}

Intracellularly recorded cells were filled with $4 \%$ neurobiotin by applying depolarizing current pulses for 5-15 min $(0.8 \mathrm{nA}, 500 \mathrm{~ms}$ duration, 1 $\mathrm{Hz})$. After electrophysiological recordings, animals were perfused transcardially with saline and $4 \%$ paraformaldehyde. The brains were then cryoprotected with $30 \%$ sucrose. Coronal sections $(50 \mu \mathrm{m})$ were cut on a freezing microtome and reacted with $2-5 \mu \mathrm{g} / \mu \mathrm{l}$ Texas Red streptavidin (Vector Laboratories). Fluorescently labeled cells were visualized on a Zeiss (Thornwood, NY) LSM 510 laser-scanning confocal microscope using a $40 \times$ objective (numerical aperture 1.3).

\section{Data analysis}

For extracellular recordings, an excitatory response was defined as an elevation in firing rate during the $2 \mathrm{~s}$ odor presentation exceeding 2 SDs of the baseline firing rate, measured during the $4 \mathrm{~s}$ prestimulus interval, and significantly larger than the firing rate change induced by mineral oil (Student's $t$ test). This second criterion was used to control for any suprathreshold and/or subthreshold activity change induced by changes in the flow rate associated with stimulus delivery or by the vehicle (mineral oil). We followed this procedure because we and others in the Katz laboratory have encountered a small subpopulation of mitral cells in the $\mathrm{MOB}$ that respond strongly to flow rate change. Although we did not observe large changes in firing rate in response to presentation of mineral oil alone, flow rate change by itself occasionally did induce a small increase in the firing rate. For intracellular recordings, both suprathreshold and subthreshold excitation was measured. A suprathreshold excitatory response was defined as an elevation in firing rate exceeding 2 SDs of the baseline firing rate in the $4 \mathrm{~s}$ prestimulus interval and significantly larger than the firing rate change induced by mineral oil (Student's $t$ test). The suprathreshold response strength shown in the Figure $4 y$-axis was calculated by subtracting the change of the firing rate above baseline induced by mineral oil from the change of the firing rate induced by the mixtures and each of their component odorants. A subthreshold excitatory response was defined as a net membrane potential depolarization during odor presentation that was significantly larger than that induced by mineral oil (Student's $t$ test). For each stimulus, responses to more than three trials (and in most cases, more than six trials) were averaged. The averaged net membrane potential change was calculated as follows. First, raw traces were median filtered (each point was replaced by the median value of the surrounding 50 points, equivalent to $5 \mathrm{~ms}$ at the 10 $\mathrm{kHz}$ sampling rate used here). Second, the subthreshold depolarizing responsiveness $\left(R_{\mathrm{Vm}}\right)$ was calculated as $R_{\mathrm{Vm}}=S_{\mathrm{Vm}}-B_{\mathrm{Vm}}$, where $S_{\mathrm{Vm}}$ is the averaged membrane potential during odor presentation and $B_{\mathrm{Vm}}$ is the averaged membrane potential in the $10 \mathrm{~s}$ prestimulus interval. Third, the subthreshold activities over the multiple trials were averaged. In all relevant figures where subthreshold responses to mixtures and/or odor- 
A
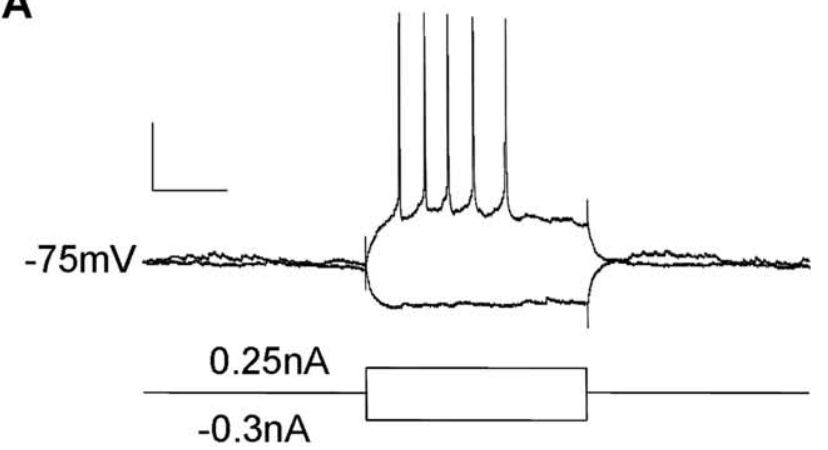

B

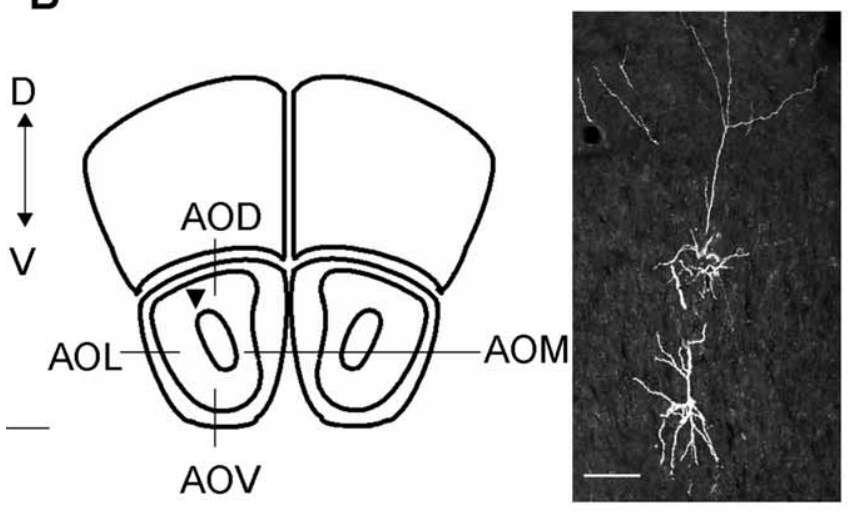

C mixture2 $(n=6)$

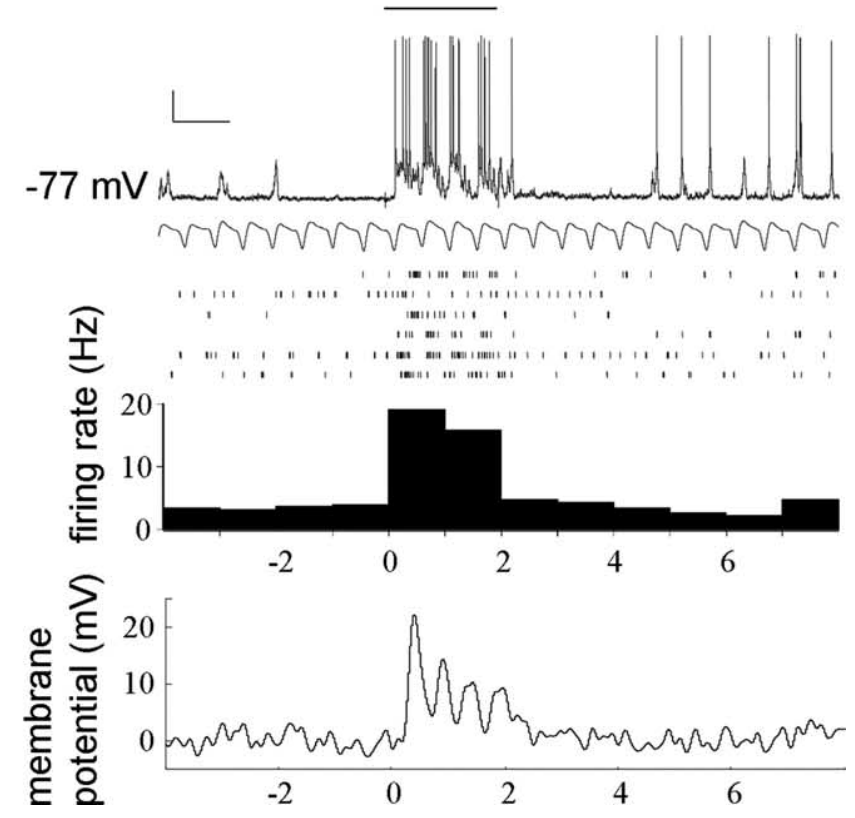

Figure 1. In vivo intracellular recording reveals odor-evoked subthreshold and suprathreshold activity of AON neurons. $A$, Membrane potential response of a typical AON neuron to injected current pulses. The resting membrane potential of this $\mathrm{AON}$ neuron was $-75 \mathrm{mV}$ without current injection. The injected current pulses were +0.25 and $-0.30 \mathrm{nA}$, respectively. Calibration: $20 \mathrm{mV}, 100 \mathrm{~ms}$. $\boldsymbol{B}$, Verification of the recording site in $\boldsymbol{C}$. Left, A schematic diagram of a coronal section of a mouse brain. D, Dorsal; V, ventral; AOD, dorsal AON; AOL, lateral AON; AOM, medial AON; AOV, ventral AON. Right, The morphology of the AON neuron recorded in $C$, as revealed by intracellular neurobiotin staining (cell body location depicted by inverted triangle in the left panel). Scale bars: left, $500 \mu \mathrm{m}$; right, $100 \mu \mathrm{m}$. C, Odor-evoked responses in a typical AON neuron. The top panel shows the intracellular recording trace and respiration activity trace. Calibration: $20 \mathrm{mV}, 1 \mathrm{~s}$. The raster plots and poststimulus time histogram in the middle panel ants are depicted, quantification of the subthreshold responses to mineral oil is also provided. As with suprathreshold responses, the mineral oil-associated activity is shown as a control for flow rate and vehicle effects. In supplemental Table 1 (available at www.jneurosci.org as supplemental material), the mixture and odorant-evoked responses were corrected for these effects by subtracting any mineral oil-evoked subthreshold response.

The 9 AON neurons used in the analysis of the nonlinear suprathreshold response to odor mixtures shown in Figure 4 were chosen from the 19 AON neurons tested by both odor mixtures and their components according to the following three criteria. First, odor mixtures or at least one component evoked a suprathreshold response. Second, no "holding" current was injected into the cell during the entire recording period. This criterion insures that we studied the response properties of the cell to mixtures and individual odorants without the possible confound of altering the distance between the resting membrane potential and action potential threshold. Third, the resting membrane potential of the cell was stable during the entire recording period. As with the second criterion, this requirement avoided cases in which fluctuations in the resting membrane potential could change the amount of synaptic activity required to reach action potential threshold.

A $\chi^{2}$ test and a Kolmogorov-Smirnov test were used to compare the distribution of the number of effective mixtures and effective components between mitral cells and AON neurons.

\section{Results}

We used intracellular and extracellular recordings in sevoflurane-anesthetized mice to record odorant-evoked responses in the AON and the MOB. We first characterized the suprathreshold and subthreshold responses of AON neurons to a panel of structurally dissimilar odorants presented as both mixtures and monomolecular components. Then, in a different set of mice of the same strain and sex, we measured the suprathreshold and subthreshold responses of mitral cells in the MOB to the same odorant panel and compared the responsiveness of AON neurons to that of their afferent mitral cells.

To activate non-overlapped mitral cells and sample as large an odor space as possible, we chose a panel of 40 dissimilar odorants broadly distributed across structural and perceptual categories, presented as both mixtures and monomolecular components at a concentration of $1 \mathrm{ppm}$. This panel was artificially divided into seven mixtures with each mixture comprising six structurally dissimilar components (with the exception of mixture 6, which only contains four components) (Table 1). Subthreshold and suprathreshold responses of $A O N$ neurons to the seven mixtures were examined first, and then after confirming that an AON neuron was activated by a given mixture, the responses of the cell to the individual components in that mixture were measured (see Materials and Methods for quantification of subthreshold and suprathreshold responses).

\section{Intracellular recording reveals that AON neurons exhibit broad responsiveness}

We used sharp electrode intracellular recording in AON neurons to measure the breadth of their odor-evoked responses. The cells that we recorded from had low spontaneous firing rates $(<5 \mathrm{~Hz})$ and had an average action potential width at half amplitude of $0.75 \pm 0.02 \mathrm{~ms}(n=43)$. In the absence of an odor stimulus, the average resting membrane potential of these AON neurons was

$\leftarrow$

show consistent suprathreshold responses. The bottom panel shows the averaged net membrane potential change. During odor presentation ( $2 \mathrm{~s}$; indicated by the black bar), the cell is strongly excited, as revealed by both an increase in the firing rate and a depolarization of membrane potential, both of which are in phase with the respiratory rhythm $(n=6)$. 
$-78.1 \pm 0.7 \mathrm{mV}(n=24$ cells that were studied without tonic current injection), and the membrane potential oscillated in synchrony with the breathing rhythm $(\sim 2-3 \mathrm{~Hz})$ during some time periods. The membrane potential response of a typical AON cell to injected current pulses is shown in Figure $1 \mathrm{~A}$. Subsequent intracellular staining with neurobiotin and post hoc visualization revealed that all $(n=32)$ of the AON neurons recovered for histology were pyramidal in shape, with one long apical dendrite extending toward the superficial lateral olfactory tract (LOT) layer, several basal dendrites, and a soma located in the cell body layer of AON (Fig. $1 B$ ). Their low spontaneous firing rates, relatively broad action potentials, and pyramidal morphology indicated that all of the cells that we recorded from were AON pyramidal neurons.

Delivery of odor stimuli evoked excitatory responses from AON neurons. Responses started at the first inhalation after stimulus onset, lasted for the full $2 \mathrm{~s}$ odor presentation, and were characterized by both membrane potential depolarization and an increase in the firing rate of the cell (Fig. 1C) (see Materials and Methods). Net membrane potential change averaged across multiple trials of the same odorant emphasize an abrupt depolarization at the first inhalation point after odor delivery and an augmented oscillatory behavior in synchrony with the breathing rhythm (Fig. 1C). Among the 83 intracellularly recorded AON neurons, 47 exhibited excitatory responses to at least one odor mixture. We never observed hyperpolarizing membrane potential responses to mixtures or component odorants.

Because intracellular recording affords the most sensitive measurement of synaptic input, we applied this technique to examine the odor-evoked subthreshold responses of $\mathrm{AON}$ neurons. We found that individual AON neurons can be activated synaptically by multiple mixtures and multiple components in an effective mixture. Among odorresponsive AON neurons tested with more than one mixture, almost all (38 of 47 , or $81 \%$ ) were activated by multiple mixtures, whereas the remainder ( 9 of 47 , or $19 \%$ ) responded to only one mixture (see Fig. $8 \mathrm{~A}$ ). Figure 2 shows an example of a broadly responsive AON neuron, which displayed subthreshold and suprathreshold responses to five mixtures.

After confirming that an AON neuron could be activated synaptically by a given mixture, subthreshold responses to the individual components of that mixture were tested separately. Of the 19 AON neurons held long enough to test both the effective mixtures and their components, 17 were activated by two or more

A

a2
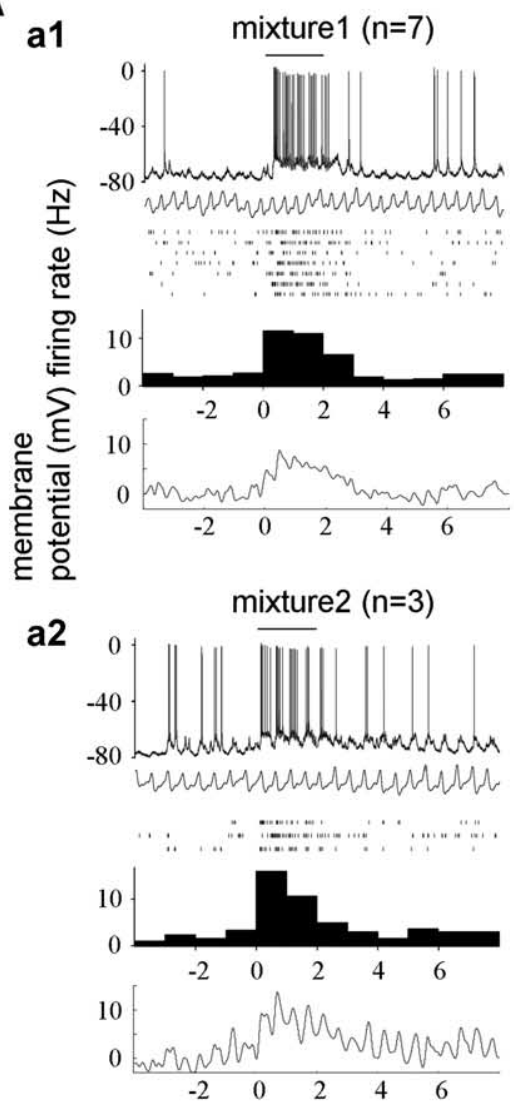

a4

mixture4 $(n=4)$
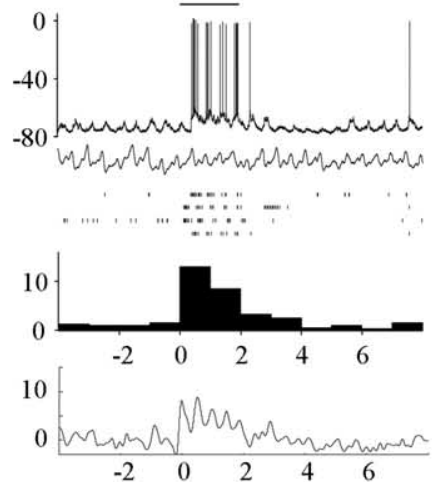

a5

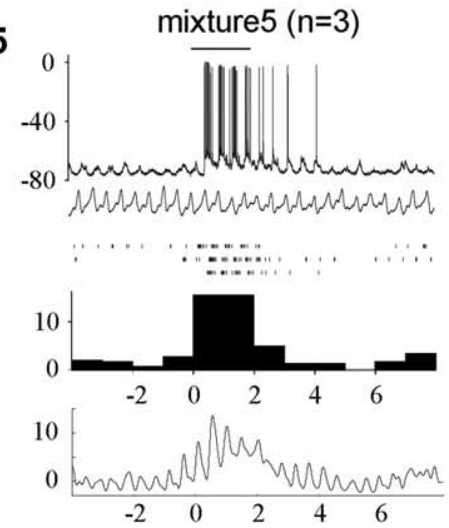

B

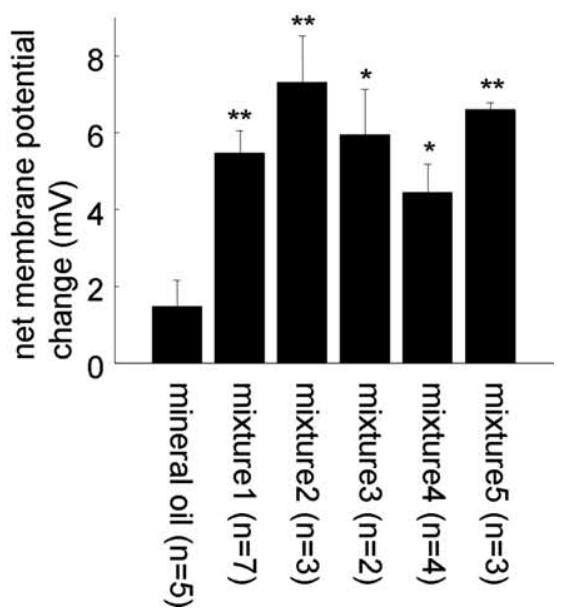

Figure 2. AON neurons can respond to multiple dissimilar mixtures. $A$, In vivo intracellular recording from an AON neuron shows that it was strongly excited by five mixtures $(\boldsymbol{a} \mathbf{1}-\boldsymbol{a} \mathbf{5})$. All five mixtures can induce depolarization of the membrane potential, accompanied by action potential discharge. Conventions are as in Figure 1. $\boldsymbol{B}$, Quantification of net membrane potential change induced by each mixture during a 2 s odor presentation. ${ }^{*} p<0.05,{ }^{* *} p<0.01$, Student's $t$ test versus mineral oil (vehicle only). components: one cell (5\%) was synaptically activated by five components, seven cells (37\%) were activated by four components, two cells (10\%) were activated by three components, seven cells $(37 \%)$ were activated by two components, and two cells $(10 \%)$ were activated by only one component (summarized in Fig. $8 \mathrm{~B}$ ). On average, AON neurons respond to three components in a given effective mixture. An exemplar AON neuron shown in Figure 3 reveals subthreshold activation by several 
A a1 mixture7 $(n=11)$

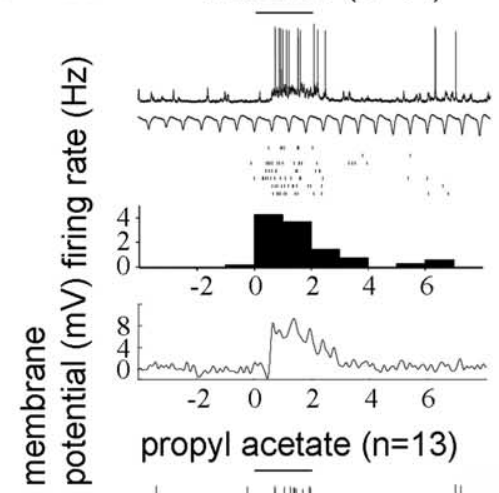

a3
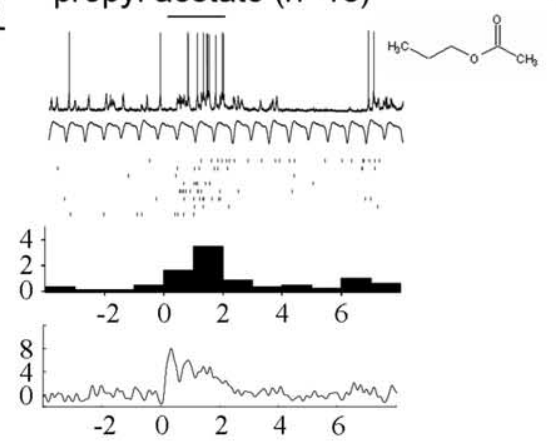

a5
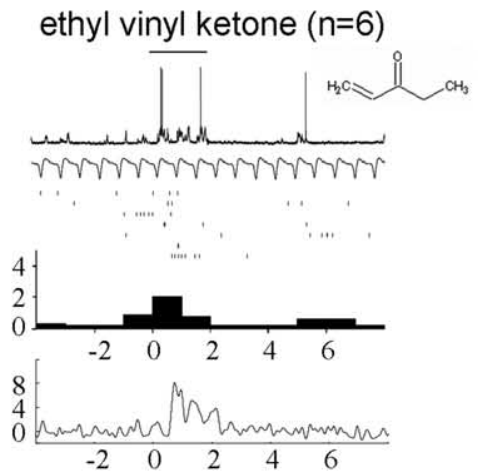

a7
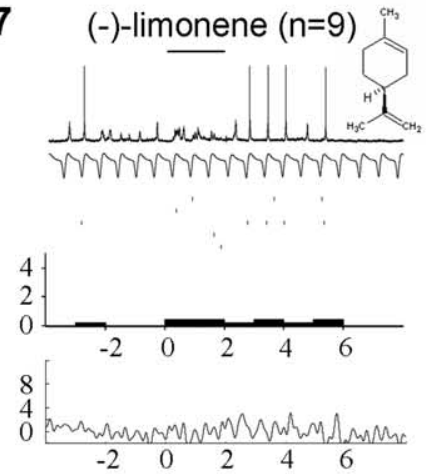

(2) a2

methyl valerate $(n=9)$
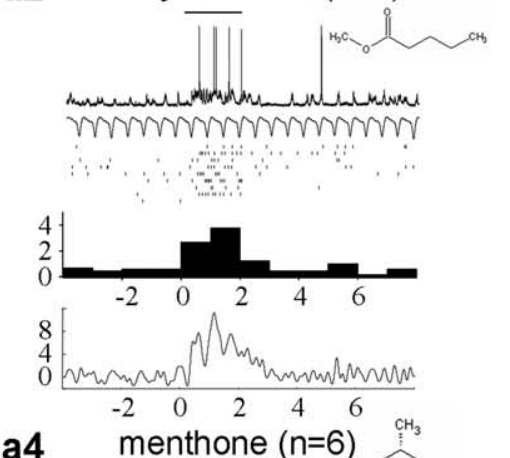

a4
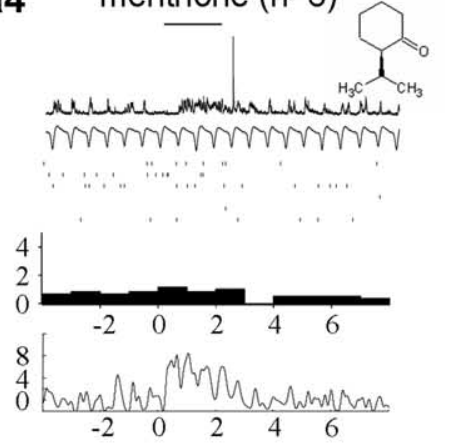

a6 methyl pyrrolyl ketone $(n=6)$
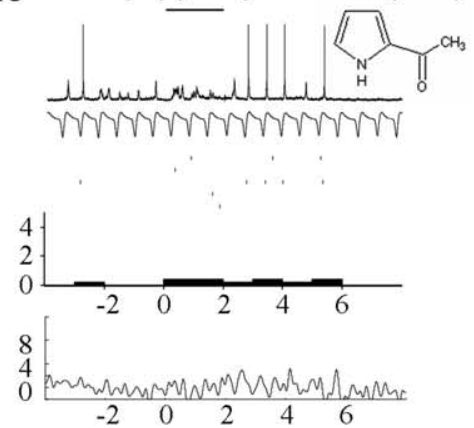

B
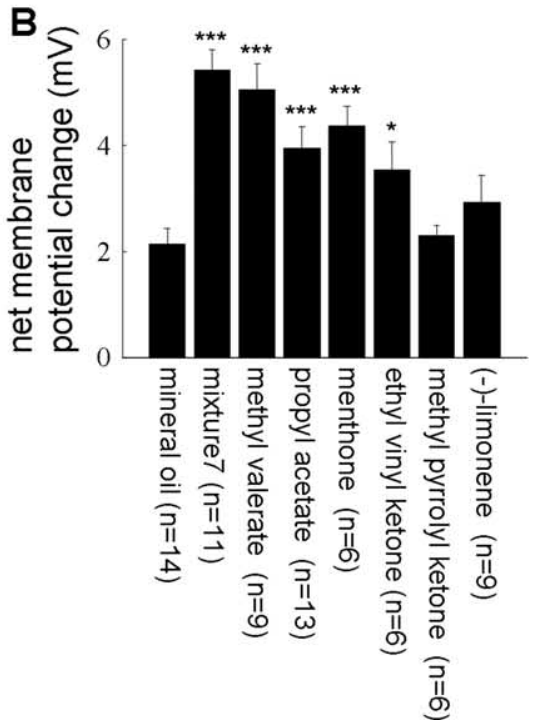

Figure 3. AON neurons can be excited by multiple dissimilar components within an effective mixture. $A$, In this example, four components of a single mixture (mixture7) induced significant subthreshold activity relative to mineral oil (data not shown). Conventions are as in Figure 1. B, Quantification of averaged net membrane potential change (subthreshold activity) induced by the entire mixture and its individual components during a 2 s odor presentation. ${ }^{*} p<0.05,{ }^{* * *} p<0.001$, Student's $t$ test versus mineral oil (vehicle only).

structurally dissimilar components from one of the effective mixtures for that cell. These results show that AON neurons can respond to a broad panel of structurally dissimilar odorants.

A previous study showed that the expression of the IEG arc in some olfactory cortical neurons requires simultaneous presentation of two odorants (Zou and Buck, 2006). These studies suggest that AON neurons may transmit information about combinations of odorants in a nonlinear manner, although the relationship between IEG expression and suprathreshold activity in the AON is not well understood. To determine whether combinations of odorants could evoke suprathreshold responses from AON neurons in a nonlinear manner, we compared the suprathreshold responsiveness of an AON neuron to an effective mixture to the sum of its suprathreshold responses to all of the components in that mixture. The nine AON neurons included in the analysis and shown in Figure 4 were chosen according to three criteria, including a suprathreshold response to at least one stimulus, a stable resting membrane potential throughout the test period, and no application of tonic current injection during the test period (see Materials and Methods). In most (six of nine) cells that met these three criteria, the suprathreshold response to the effective mixture exceeded the sum of the suprathreshold responses to all individual components within that mixture (Fig. 4, cells 1-6) (note that these suprathreshold responses to mixtures and their component odorants are corrected for any vehicle or flow rate effects by subtracting responses to mineral oil presented alone). In the other three cells, the suprathreshold response evoked by the mixture was either smaller than $(n=2)$ or equal to $(n=1)$ the linear sum of component-evoked responses. This set of experiments suggests that AON neurons show nonlinear suprathreshold responses to multiple odorants presented as a mixture. One explanation for the supralinear behavior that we observed is that many component odorants may evoke only subthreshold responses when presented alone. A comparison of subthreshold and suprathreshold responses to component odorants showed this to be the case (supplemental Table 1, available at www. jneurosci.org as supplemental material) (the mean number of components in an effective mixture that elicited suprathreshold responses significantly greater than mineral oil was 0.9 ; the mean number of components in an effective mixture that 


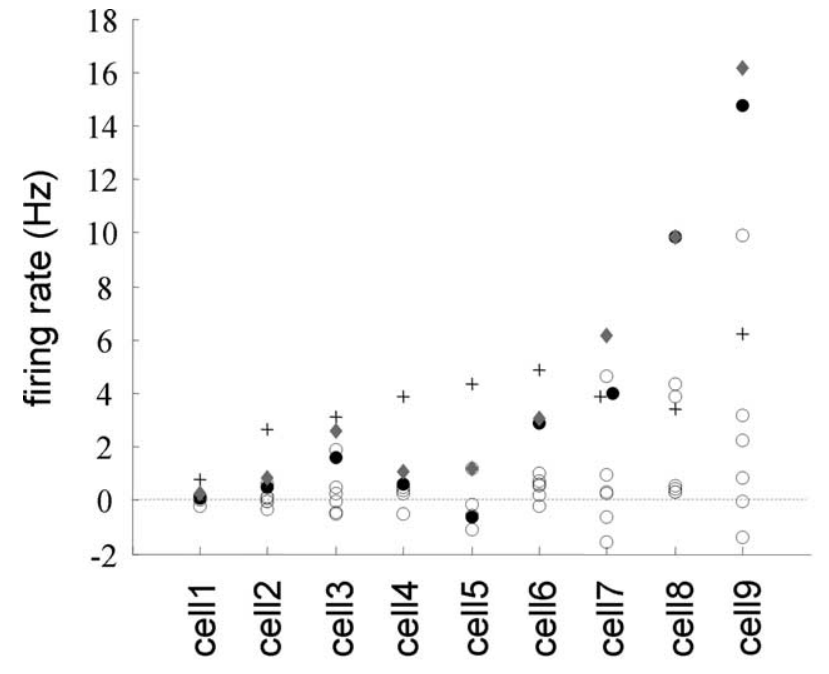

+ suprathreshold responses to mixtures

- suprathreshold responses to individual components

\section{- sum of suprathreshold responses to all} components in a given mixture

- sum of only positive suprathreshold responses to components in a given mixture

Figure 4. In the AON, the suprathreshold response to an effective mixture differed from the linear sum of the suprathreshold responses to all individual components in that mixture. For each of nine AON neurons, the evoked suprathreshold response to an effective mixture (cross) is compared with the suprathreshold responses to the odorants in that mixture (open circles), the sum of all of these individual odorant responses (filled circles), and the sum of only the individual odorant responses that involved a positive change in firing rate (diamonds). In most cells (1-6), the suprathreshold response to the mixture exceeded either of the linear sums, whereas in the other three cells (7-9), the mixture-evoked response was less than or equal to the linear sums. In all cases, the odor-evoked firing rate was calculated relative to presentation of the vehicle alone (i.e., mineral oil) to control for any flow rate and/or vehicle-dependent changes in firing rate in these AON neurons (see Materials and Methods).

elicited subthreshold responses significantly greater than mineral oil was $2.9 ; p=0.002$, paired $t$ test; $n=9$ cells). The sublinear responses to mixtures we saw in two cells may provide some evidence of inhibitory processes (see Discussion).

Mitral cells in the MOB exhibit narrower responsiveness than do AON neurons

Previous studies show that mitral cells in the MOB are narrowly tuned, typically responding to odorants with high structural similarity (Mori, 1995; Mori et al., 1999) (I. Davison and L. C. Katz, unpublished observations). To confirm that the 40 structurally dissimilar odorants in our odor panel do indeed activate disparate mitral cells, we measured the suprathreshold and subthreshold responses of mitral cells to the same odorant panel used to assess AON neuronal responsiveness. This allowed us to directly compare the relative breadth of responsiveness of AON neurons and their primary afferents.

We first used sharp electrodes to make intracellular recordings from mitral cells in the MOB (Fig. 5). In the absence of an odor stimulus, the average resting membrane potential of mitral cells was $-66.6 \pm 1.0 \mathrm{mV}(n=25$ cells that were studied without tonic current injection). Delivery of odor stimuli evoked excitatory responses characterized by both membrane potential depo-
A

mixture3 $(n=8)$

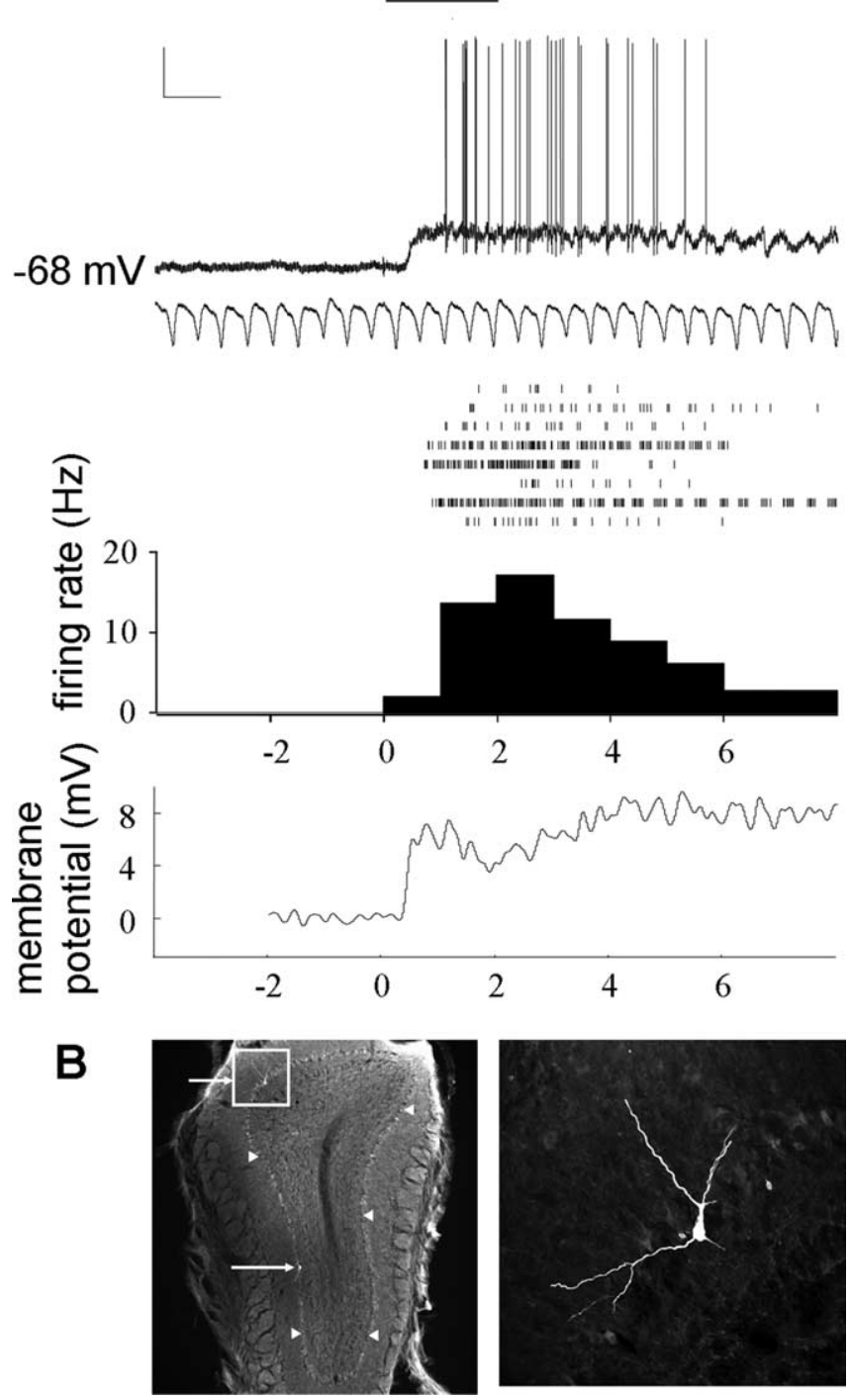

Figure 5. In vivo intracellular recording reveals both suprathreshold and subthresohold responses of mitral cells. $A$, A representative response of a mitral cell to presentation of an odor mixture. Odor presentation consistently evokes both suprathreshold and subthreshold responses of the mitral cell across multiple trials $(n=8)$. Conventions are as in Figure 1. Calibration: $20 \mathrm{mV}, 1 \mathrm{~s} . \boldsymbol{B}$, Intracellular neurobiotin staining reveals recorded cells are situated in the mitral cell layer. The mitral cell layer is designated by arrowheads, and two filled cells are indicated by arrows. The right panel shows a higher-magnification image of the cell within the boxed region of the left panel.

larization and an increase in firing rate (Fig. 5A). We observed that at both subthreshold and suprathreshold levels, most responsive mitral cells were activated by only a single component of a single effective mixture (Figs. 6, 7). Among the 35 intracellularly recorded mitral cells ( $n=14$ mice), 24 cells were entirely unresponsive to any of the odorant mixtures, whereas nine were activated by only one mixture (Fig. 6) and two were activated by three mixtures. Of the six responsive mitral cells held long enough to measure the responses to individual components in effective mixtures, five $(83 \%)$ exhibited excitatory responses to only one component (Fig. $7 A, B$ ) and only one (17\%) responded to two components in a single mixture. Notably, the strength of the subthreshold and suprathreshold excitation evoked by a single component was similar to that evoked by the entire mixture (Fig. 
A
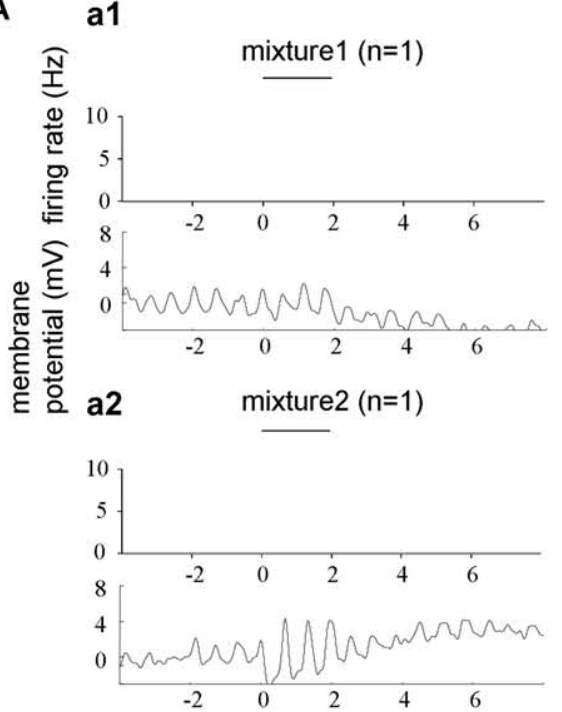

a3

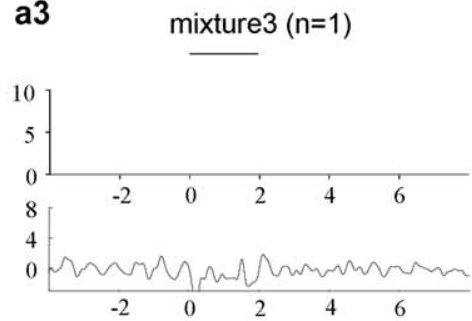

a4

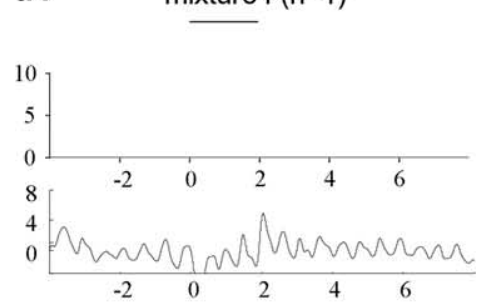

a5


a6

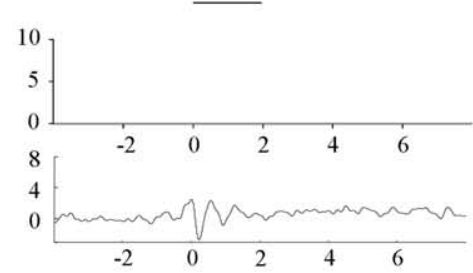

a7

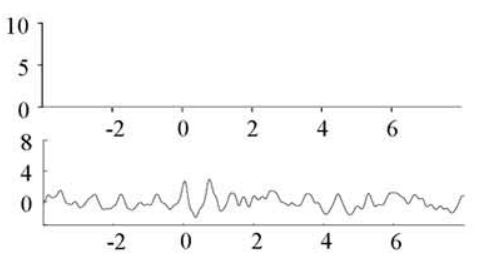

B

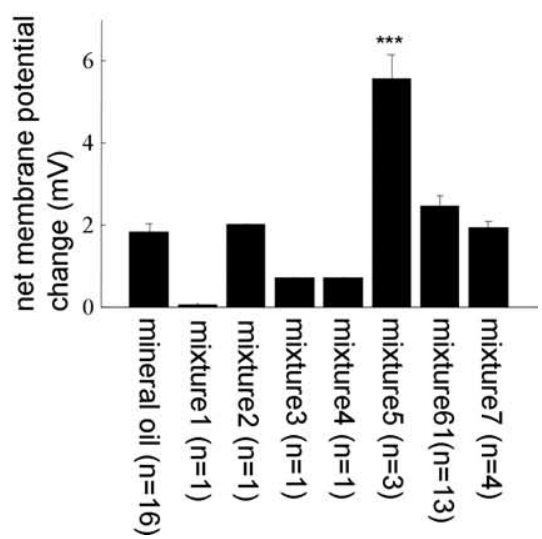

Figure 6. Intracellular recording reveals most mitral cells respond to only one of seven test mixtures. $A$, A mitral cell is activated only by mixture $5 . \boldsymbol{a 1}-\boldsymbol{a 7}$, The top panel shows the raster plots and poststimulus time histogram constructed from presentation of the seven mixtures. The bottom panel shows the net membrane potential change during odor stimulation. Only mixture 5 induces responses. The number of stimulus presentations is shown in parentheses. $\boldsymbol{B}$, Quantification of net membrane potential change induced by each mixture during odor delivery. ${ }^{* * *} p<0.001$, Student's $t$ test versus mineral oil (vehicle only).

$7 B)$, suggesting that a single component can fully account for the response to the mixture.

Because only suprathreshold activity can be transmitted from mitral cells to AON neurons, we also used extracellular recordings to measure mitral cell responses to the same odor panel. Among the 44 mitral cells ( $n=6$ mice) we studied with extracellular recordings, 37 were entirely unresponsive to any of the odorant mixtures, whereas three were activated by only one mixture and four were activated by multiple mixtures. Although the percentage of mitral cells responding to multiple mixtures measured by extracellular recording was larger than that measured by intracellular recording (extracellular vs intracellular: 4 of 44 vs 2 of 35), most mitral cells still were activated by only one or two components in an effective mixture. In the 10 cases in which one or more component in an effective mixture elicited a response from a mitral cell, six $(60 \%)$ of these responses were to only one component in a given effective mixture (supplemental Fig. 1, available at www.jneurosci.org as supplemental material), three $(30 \%)$ were to two components, and one (10\%) was to three components. Finally, to exclude the possibility that the lack of responses to certain mixtures was attributable to cancellation of responses between mutually inhibitory components (Oka et al., 2004; Tabor et al., 2004), the responses of all $(n=44)$ cells to individual components of a randomly chosen noneffective mixture were also examined. No responses to individual components in noneffective mixtures were found, reinforcing the idea that mitral cells only respond to a very small fraction of odorants in our panel. This is consistent with previous findings showing that individual mitral cells respond to structurally similar, but not dissimilar, odorants (Mori, 1995; Mori et al., 1999).

To better estimate the behavior of the mitral cell population, we combined odorant response measurements from cells examined with intracellular and extracellular recordings. We combined these two pools of cells because a $\chi^{2}$ test revealed that the numbers of components in an effective mixture to which mitral cells respond when measured with intracellular or extracellular recordings were drawn from the same distribution ( $\chi^{2}$ test, $p=$ 0.83 ). These pooled data revealed that more than two-thirds ( 11 of 16 , or $69 \%$ ) of mitral cells responded to only one component in a mixture, whereas $25 \%$ (4 of 16 ) responded to two components and $6 \%(1$ of 16) responded to three components (Fig. $8 \mathrm{~B}$ ). Furthermore, two-thirds (12 of 18) of the responsive mitral cells were activated by only one mixture, whereas onethird (6 of 18) were activated by multiple mixtures (Fig. $8 A$ ). These recordings show that the majority of mitral cells respond to only a single odorant within a single effective mixture. This tendency to respond to one of the structurally dissimilar odorants in our panel distinguishes mitral cells from AON neurons.

To quantify population level differences in mitral cell output and $\mathrm{AON}$ cell input, we compared the suprathreshold response profiles of mitral cells with the subthreshold response profiles of AON neurons to the same odorant panel. The distribution of mitral cell and AON neuron responses to the number of mixtures $\left(\chi^{2}\right.$ test, $\left.p<0.0001\right)$ (Fig. $8 A$ ) or the number of components in an effective mixture ( $\chi^{2}$ test, $p<0.0001$ ) (Fig. $8 B$ ) were significantly different. This comparison supports the idea that AON neurons exhibit a broader range of synaptic responsiveness to 
mixtures and individual odorants than can be accounted for by the suprathreshold responses of individual mitral cells.

\section{Discussion}

We used both extracellular and intracellular recordings to compare the responsiveness of AON neurons with their afferent mitral cells to the same panel of odorants. We found that, as a population, AON neurons exhibit broader receptive fields than do mitral cells: most AON neurons were synaptically excited by multiple mixtures and several components in an effective mixture, whereas the majority of mitral cells responded to only one or two components in an effective mixture. We also observed that AON neurons could respond in a nonlinear manner to combinations of odorants within an effective mixture. These results point to the $\mathrm{AON}$ as a site where individual odorant features are combined to generate broader and more complex response patterns.

The broader response patterns of $\mathrm{AON}$ neurons indicate that individual AON neurons integrate multiple synaptic inputs from a population of functionally diverse mitral cells. This interpretation is strengthened by evidence that many of the odorants that individual $\mathrm{AON}$ neurons respond to are known to activate non-overlapping populations of mitral cells, as revealed by 2-deoxyglucose (2-DG) and intrinsic imaging methods. For example, we found that two AON neurons responded to two components in mixture 6, 2-hexanone and heptanal, which have mutually exclusive activation patterns in the MOB as determined by the 2-DG method (Leon and Johnson, 2006). Similarly, one AON neuron responded to ethyl butyrate and (-)-carvone in mixture 1 , and another AON neuron responded to 2-pentanone and eugenol in mixture 3. Each member of these odorant pairs also activates disparate regions of the MOB (Leon and Johnson, 2006). More evidence comes from intrinsic imaging experiments. Two AON neurons we recorded from were activated by both $(-)$-carvone and pinene in mixture 1 , which activate distinct populations of mitral cells as determined by intrinsic imaging methods (Takahashi et al., 2004). Similarly, one AON neuron responded to methyl valerate, propyl acetate, and (-)-limonene, and another AON neuron responded to methyl valerate, propyl acetate, and menthone in mixture 7. These odors also activate different regions of the MOB (Uchida et al., 2000; Takahashi et al., 2004; Mori et al., 2006). Nevertheless, a minority of the mitral cells in our sample exhibited broad
A a1 mixture2 $(n=5)$

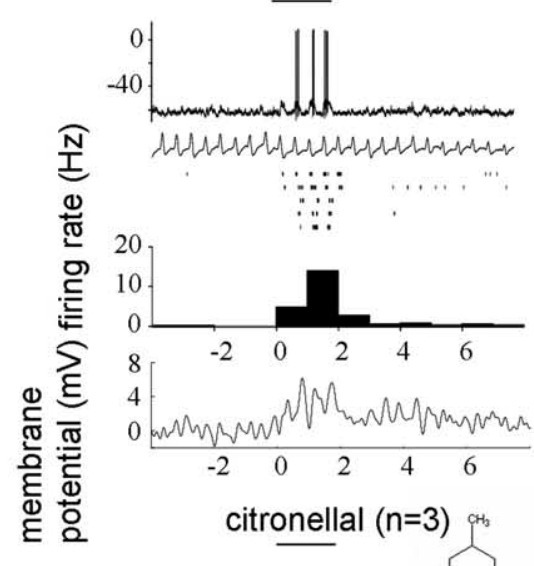

a3
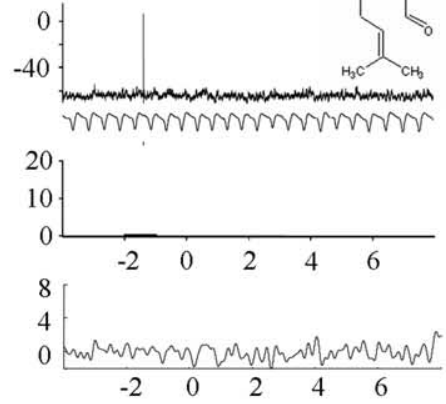

a5
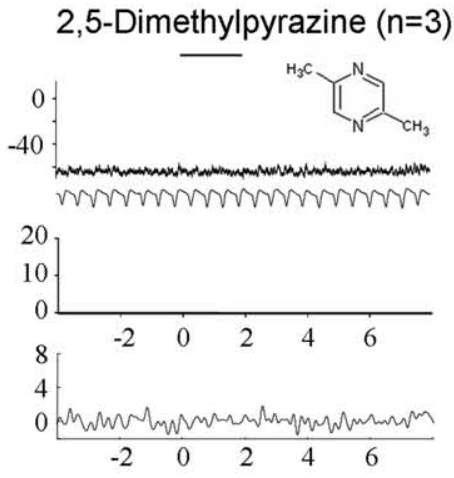

a7

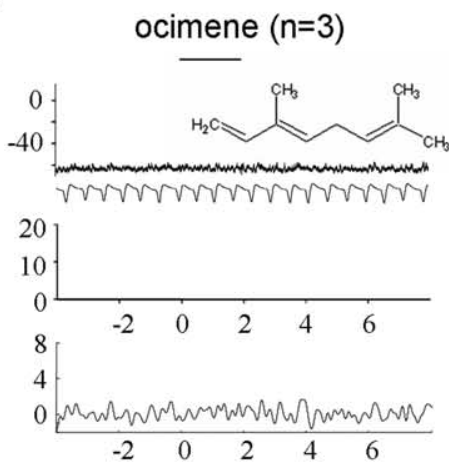

a2

methylbenzene $(n=6)$
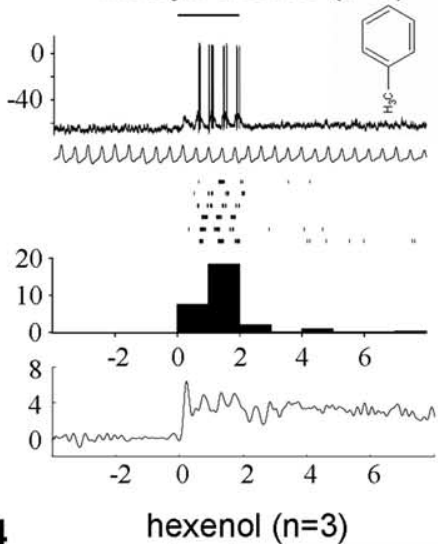

a4
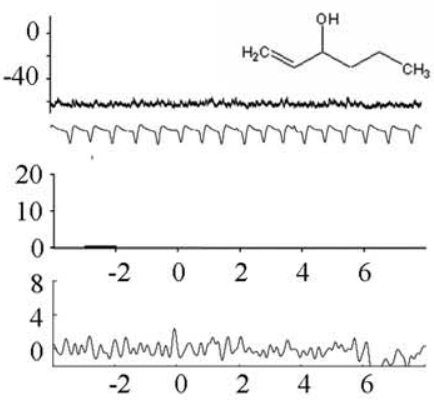

a6 isovaleric acid $(n=3)$
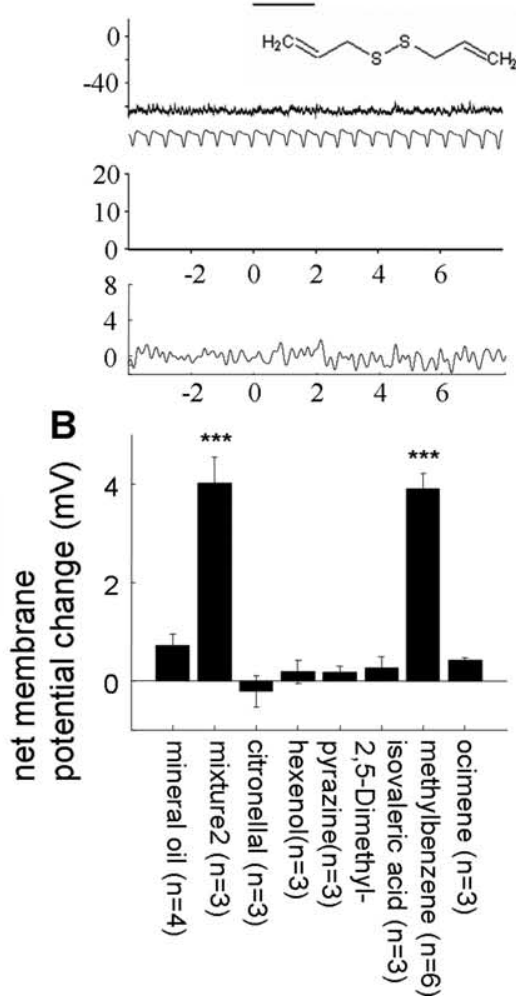

Figure 7. Most mitral cells respond to only a single component in an effective mixture. $A$, A representative mitral cell responds to only a single component (methylbenzene) in mixture 2.a1-a7, The entire mixture 2 and a single component of that mixture, methylbenzene, reliably evoke suprathreshold and subthreshold responses. The other five components fail to evoke any responses. The strength of suprathreshold activity and the magnitude of membrane potential depolarization induced by component methylbenzene in isolation are similar to those induced by the entire mixture 2. The number of stimulus presentations is given in parentheses. Conventions are as in Figure 1. B, Quantification of net membrane potential change induced by the entire mixture 2 and its individual components. ${ }^{* *} p<0.001$, Student's $t$ test versus mineral oil. The entire mixture 2 and its component methylbenzene induce subthreshold activity significantly larger than mineral oil, which serves as a vehicle-only control. 
A

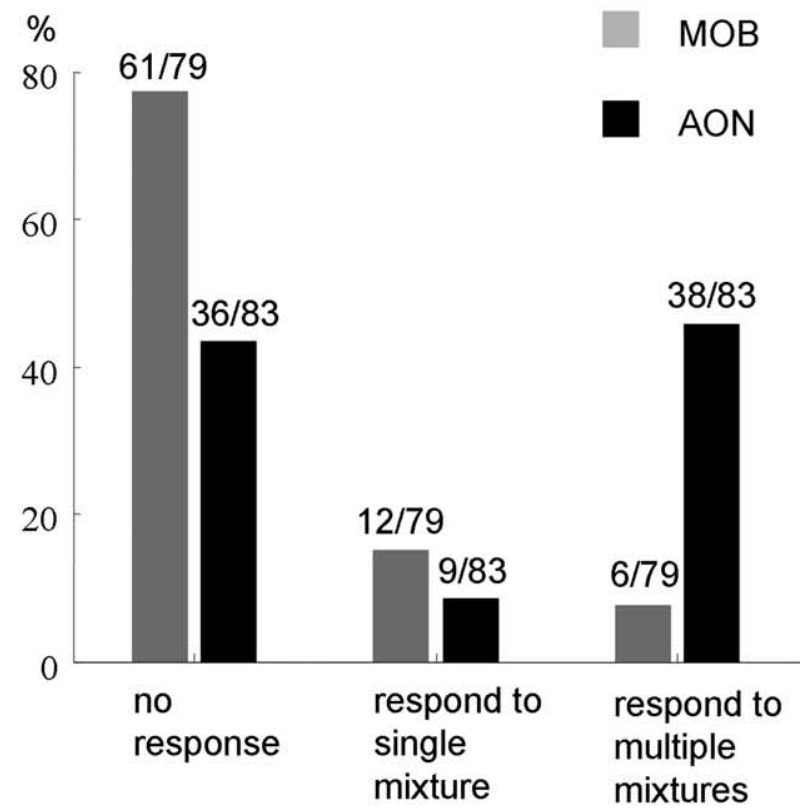

B responsive cells

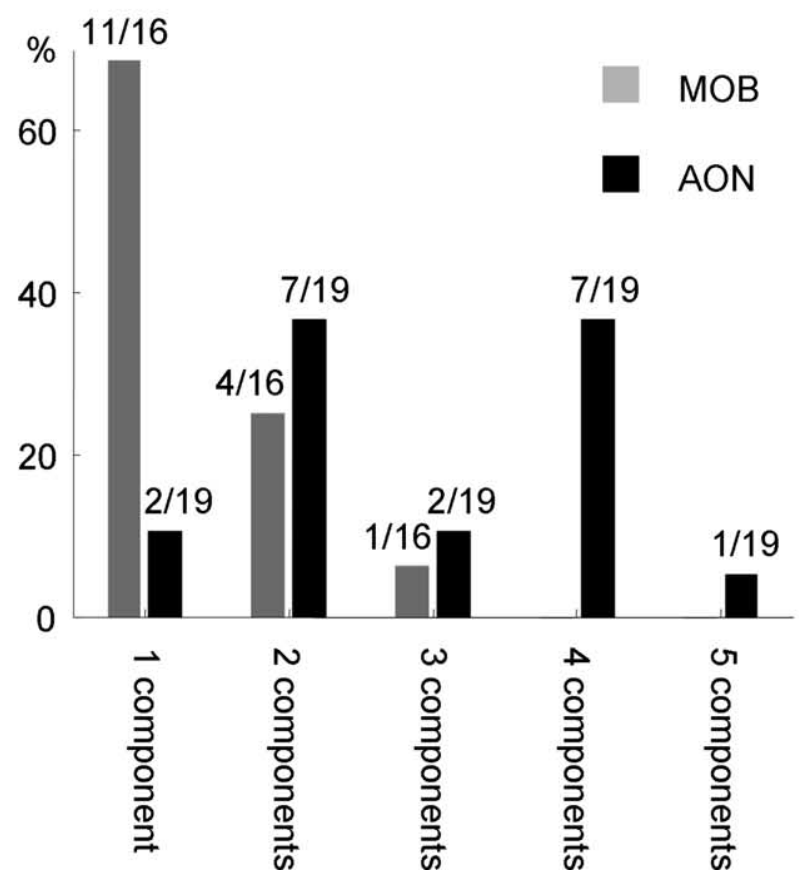

Figure 8. Comparison of suprathreshold response profiles in mitral cells with subthreshold response profiles in $A O N$ neurons reveals that $A O N$ neurons are more broadly responsive at the synaptic level than are mitral cells at the output level. $A$, The number of mixtures that elicit subthreshold responses in individual AON neurons (black bar) exceeds the number of mixtures that elicit suprathreshold responses in individual mitral cells (gray bar) $\left(\chi^{2}\right.$ test, $\left.p=0\right)$. $\boldsymbol{B}$, More AON neurons respond to multiple components of an effective mixture than do mitral cells $\left(\chi^{2}\right.$ test, $p=4.4 \mathrm{e}-12$ ).

response characteristics that could also contribute to the greater breadth of tuning patterns observed in the AON.

The transform from narrowly tuned mitral cells to broadly tuned AON neurons could be mediated by the direct convergence of mitral cell axons onto individual AON neurons. Evidence for direct mitral cell to AON neuron convergence comes from anatomical studies showing that axon collaterals arising from different glomeruli may partially overlap in the olfactory cortex (Zou et al., 2001) and from physiological studies showing that individual olfactory cortical neurons receive convergent synaptic input from the LOT (Franks and Isaacson, 2006). Alternatively, this transform may be mediated by intracortical or corticocortical connections through the well developed association fiber network (Neville and Haberly, 2004). Intracellular staining of single olfactory cortical neurons reveals that their synaptic terminals ramify broadly throughout the entire olfactory cortex (Luskin and Price, 1983a,b; Ojima et al., 1984; Johnson et al., 2000), providing the likely source of the disynaptic EPSPs evoked in olfactory cortical neurons by electrical stimulation of the LOT (Neville and Haberly, 2004). Therefore, abundant synaptic substrates for both direct and indirect convergence exist between the MOB and the AON and could account for the broad patterns of synaptic responsiveness in AON neurons we detected. Distinguishing between direct and indirect mechanisms could be achieved by recording intracellularly from AON neurons while reversibly inactivating the local AON circuit (Ferster et al., 1996) or pharmacologically isolating afferent versus associational inputs to AON neurons (Hasselmo and Bower, 1992; Tang and Hasselmo, 1994; Franks and Isaacson, 2005). Ultimately, the present observations support a convergent organization between the MOB and the AON, regardless of the underlying mechanism.

The present study reveals some features of synaptic integration at the level of the AON and thus constitutes an initial step in linking cellular and synaptic level events to higher-order aspects of olfactory processing. One feature we noted was that AON neurons often responded in a nonlinear manner to combinations of odorants presented as mixtures. The most common behavior we observed was a mixture-evoked suprathreshold response that exceeded the linear sum of suprathreshold responses to all components of that mixture. This supralinear behavior indicates that AON neurons can effectively signal the presence of odorant combinations, consistent with recent studies using IEG methods (Zou and Buck, 2006). The most likely explanation for this behavior is that individual odorants presented in isolation often elicit only subthreshold synaptic responses, but interactions between synaptic responses evoked by odorants presented in mixtures exceed action potential threshold. This view is supported by the present finding that individual odorants more often evoked only subthreshold responses (supplemental Table 1, available at www. jneurosci.org as supplemental material). We also observed sublinear responses to odorant mixtures in a smaller subset of cells, which might point to inhibitory processes. Although we never saw hyperpolarizing membrane potential responses to any components or mixtures, the relatively negative resting potentials of AON neurons we recorded from raises the possibility of depolarizing inhibitory synaptic activity (i.e., if the resting membrane potential was negative of the reversal potential of the inhibitory current). Indeed, one hint of inhibition is that the suprathreshold responsiveness of some AON neurons to an odorant was less than its responsiveness to presentation of vehicle only. Because the projections from the MOB to the $\mathrm{AON}$ are thought to be purely excitatory (Neville and Haberly, 2004), odorant-evoked inhibition in AON neurons would likely reflect intracortical processing. An important goal of future studies will be to further dissect the synaptic mechanisms underlying olfactory responses of AON neurons, which may be achieved in part through in vivo wholecell recording methods.

Previous studies have noted striking similarities between the 
olfactory systems of diverse species ranging from insects to mammals (Ache and Young, 2005). At the periphery, olfactory receptor proteins in both insects and mammals are seven transmembrane G-protein-coupled receptors coded by a similar gene family (Buck and Axel, 1991; Clyne et al., 1999; Gao and Chess, 1999; Vosshall et al., 1999). An intriguing structural parallel is that olfactory receptor neurons expressing the same olfactory receptor make convergent projections onto second-order neurons, which are located in the antennal lobe of the insect or the MOB of the mammal. Subsequently, these second-order neurons make divergent projections to their respective targets in the insect protocerebrum and the mammalian olfactory cortex, and evidence suggests that multiple second-order neurons with different response properties may converge on a single postsynaptic thirdorder neuron (Zou et al., 2001; Marin et al., 2002; Wong et al., 2002). This extensive pattern of anatomical divergence and convergence between second- and third-order neurons in these systems may facilitate integration of olfactory information, including the combination of multiple odorant features present in complex natural stimuli. Evidence of such combinatorial interactions can be found in both the insect and mammalian olfactory system. In the locust, electrophysiological recordings indicate that Kenyon cells in the mushroom body may act as coincidence detectors of multiple projection neuron inputs (Perez-Orive et al., 2002). In the mouse, the electrophysiological recordings we made from the AON, as well as a recent IEG study, indicate that individual $\mathrm{AON}$ neurons can respond in a nonlinear manner to combinations of odorants. The present results extend the functional parallel between rodent and insect olfactory systems by showing that the third-order neurons of the AON synaptically integrate diverse mitral cell inputs, combining multiple odorant features at the level of single neurons in the service of complex olfactory object representation.

\section{References}

Ache BW, Young JM (2005) Olfaction: diverse species, conserved principles. Neuron 48:417-430.

Brunjes PC, Illig KR, Meyer EA (2005) A field guide to the anterior olfactory nucleus (cortex). Brain Res Brain Res Rev 50:305-335.

Buck L, Axel R (1991) A novel multigene family may encode odorant receptors: a molecular basis for odor recognition. Cell 65:175-187.

Clyne PJ, Warr CG, Freeman MR, Lessing D, Kim J, Carlson JR (1999) A novel family of divergent seven-transmembrane proteins: candidate odorant receptors in Drosophila. Neuron 22:327-338.

Ferster D, Chung S, Wheat H (1996) Orientation selectivity of thalamic input to simple cells of cat visual cortex. Nature 380:249-252.

Franks KM, Isaacson JS (2005) Synapse-specific downregulation of NMDA receptors by early experience: a critical period for plasticity of sensory input to olfactory cortex. Neuron 47:101-114.

Franks KM, Isaacson JS (2006) Strong single-fiber sensory inputs to olfactory cortex: implications for olfactory coding. Neuron 49:357-363.

Gao Q, Chess A (1999) Identification of candidate Drosophila olfactory receptors from genomic DNA sequence. Genomics 60:31-39.

Haberly LB (2001) Parallel-distributed processing in olfactory cortex: new insights from morphological and physiological analysis of neuronal circuitry. Chem Senses 26:551-576.

Hasselmo ME, Bower JM (1992) Cholinergic suppression specific to intrinsic not afferent fiber synapses in rat piriform (olfactory) cortex. J Neurophysiol 67:1222-1229.

Illig KR, Haberly LB (2003) Odor-evoked activity is spatially distributed in piriform cortex. J Comp Neurol 457:361-373.

Johnson DM, Illig KR, Behan M, Haberly LB (2000) New features of con- nectivity in piriform cortex visualized by intracellular injection of pyramidal cells suggest that "primary" olfactory cortex functions like "association" cortex in other sensory systems. J Neurosci 20:6974-6982.

Leon M, Johnson BA (2006) Glomerular activity response archive. Retrieved October 31, 2006, from http://leonserver.bio.uci.edu/index.jsp.

Lin da Y, Zhang SZ, Block E, Katz LC (2005) Encoding social signals in the mouse main olfactory bulb. Nature 434:470-477.

Lin da Y, Shea SD, Katz LC (2006) Representation of natural stimuli in the rodent main olfactory bulb. Neuron 50:937-949.

Livermore A, Laing DG (1996) Influence of training and experience on the perception of multicomponent odor mixtures. J Exp Psychol Hum Percept Perform 22:267-277.

Luskin MB, Price JL (1983a) The topographic organization of associational fibers of the olfactory system in the rat, including centrifugal fibers to the olfactory bulb. J Comp Neurol 216:264-291.

Luskin MB, Price JL (1983b) The laminar distribution of intracortical fibers originating in the olfactory cortex of the rat. J Comp Neurol 216:292-302.

Marin EC, Jefferis GS, Komiyama T, Zhu H, Luo L (2002) Representation of the glomerular olfactory map in the Drosophila brain. Cell 109:243-255.

Mori K (1995) Relation of chemical structure to specificity of response in olfactory glomeruli. Curr Opin Neurobiol 5:467-474.

Mori K, Nagao H, Yoshihara Y (1999) The olfactory bulb: coding and processing of odor molecule information. Science 286:711-715.

Mori K, Takahashi YK, Igarashi KM, Yamaguchi M (2006) Maps of odorant molecular features in the mammalian olfactory bulb. Physiol Rev $86: 409-433$.

Neville KR, Haberly LB (2004) Olfactory cortex. In: The synaptic organization of the brain (Shepherd GM, ed), pp 415-454. New York: Oxford UP

Ojima H, Mori K, Kishi K (1984) The trajectory of mitral cell axons in the rabbit olfactory cortex revealed by intracellular HRP injection. J Comp Neurol 230:77-87.

Oka Y, Omura M, Kataoka H, Touhara K (2004) Olfactory receptor antagonism between odorants. EMBO J 23:120-126.

Perez-Orive J, Mazor O, Turner GC, Cassenaer S, Wilson RI, Laurent G (2002) Oscillations and sparsening of odor representations in the mushroom body. Science 297:359-365.

Tabor R, Yaksi E, Weislogel JM, Friedrich RW (2004) Processing of odor mixtures in the zebrafish olfactory bulb. J Neurosci 24:6611-6620.

Takahashi YK, Kurosaki M, Hirono S, Mori K (2004) Topographic representation of odorant molecular features in the rat olfactory bulb. J Neurophysiol 92:2413-2427.

Tang AC, Hasselmo ME (1994) Selective suppression of intrinsic but not afferent fiber synaptic transmission by baclofen in the piriform (olfactory) cortex. Brain Res 659:75-81.

Uchida N, Takahashi YK, Tanifuji M, Mori K (2000) Odor maps in the mammalian olfactory bulb: domain organization and odorant structural features. Nat Neurosci 3:1035-1043.

Vosshall LB, Amrein H, Morozov PS, Rzhetsky A, Axel R (1999) A spatial map of olfactory receptor expression in the Drosophila antenna. Cell 96:725-736.

Wilson DA (2000a) Odor specificity of habituation in the rat anterior piriform cortex. J Neurophysiol 83:139-145.

Wilson DA (2000b) Comparison of odor receptive field plasticity in the rat olfactory bulb and anterior piriform cortex. J Neurophysiol 84:3036-3042.

Wilson DA, Stevenson RJ (2003) The fundamental role of memory in olfactory perception. Trends Neurosci 26:243-247.

Wong AM, Wang JW, Axel R (2002) Spatial representation of the glomerular map in the Drosophila protocerebrum. Cell 109:229-241.

Zou Z, Buck LB (2006) Combinatorial effects of odorant mixes in olfactory cortex. Science 311:1477-1481.

Zou Z, Horowitz LF, Montmayeur JP, Snapper S, Buck LB (2001) Genetic tracing reveals a stereotyped sensory map in the olfactory cortex. Nature 414:173-179.

Zou Z, Li F, Buck LB (2005) Odor maps in the olfactory cortex. Proc Natl Acad Sci USA 102:7724-7729. 